\title{
Harnessing New Technologies to Teach Academic Writing to the Net Generation
}

\author{
Sean Wiebe and Sandy Mcauley
}

University of Prince Edward Island

\begin{abstract}
While the ubiquity of Web 2.0 technologies disrupts conventional notions of schooling and literacy, its impact on learning is idiosyncratic at best. Taking the form of a dialogue based on the 15-week collaboration of two colleagues implementing an innovative 1st-year university writing course, this paper documents some of the successes and challenges they faced as they sought to create a space for those technologies in their classrooms.
\end{abstract}

Keywords: Web 2.0; schooling and literacy; teaching and learning; higher education; new technologies 


\section{Harnessing New Technologies to Teach Academic Writing to the Net Generation}

\section{Introductory Notes}

Inviting teachers from a variety of backgrounds to think broadly and critically about writing instruction has been a decades-long struggle. The push-pull relationship of academic writing with emerging forms of writing in social media has been a significant area of tension for writing teachers (Rice, 2006), a tension that we both faced in teaching a new writing course at the University of Prince Edward Island (UPEI). The following critical narrative inquiry explores the nature of that tension in curriculum development, implementation, and in teaching strategies.

Critical narrative inquiry, as we have used it here, is a theoretical position which foregrounds story and dialogue as a means of inquiry and representation of research. Assumed in such a position is that experiences and phenomenon are complex, multiple, and discursive in nature, and that our necessarily partial understandings of the evidence are valuable because of their connection to our specific day-to-day practices of teaching writing. Stanley and Temple (2008) note that the importance of narrative inquiry is "undoubted" (p. 275), citing its "widespread academic engagement" and "broad developments" in the social sciences (p. 275). Also assumed in the critical narrative stance is that our researchers' reflections are a means to shift, displace, question, and trouble institutional and cultural norms. In these two assumptions we acknowledge, as Bloome (2006) suggests, that theory does influence the evidence, but not to such a degree that "researchers are either trapped in a relativistic or egotistic space" (p. 143).

Our inquiry is placed in the context of teaching first-year university students a new course, Global Issues 151 (GI151), which replaced "English 101" at the UPEI as an attempt to keep pace with technology and globalization as dominant forces of change (New London Group, 2000). A preparatory course for academic writing at the university level, GI151 had the parallel goal to challenge students' conceptions of what counted as writing in an increasingly interconnected Web 2.0 world. Even noting that one course "replaced" another hints at the tension outlined above.

We have chosen in this narrative to identify our voices separately as "Sean" and "Sandy." As the narrative unfolds, our differing contexts provide important perspectives from which to view curriculum tensions with respect to writing and technology. Our narratives also include the conversations about our readings, those texts which have been layered through our experiences, themselves always a new experience of re-reading (Wiebe \& Snowber, 2009), and taken together are a means to interpret and reinterpret our classroom experiences. Narrated knowledge corresponds to our understanding of our experienced reality of the everyday, and following Bruner (1985), "is concerned with the explication of human intentions in the context of action" (p. 100).

Our shared openness to change and eagerness to experiment has brought about this collaboration. As a method, narrative inquiry aptly illustrates how experience and phenomenon change with time. Our collaborative approach is informed by 15 classroom visits that took place as part of a mentoring program. Sean attended Sandy's section at 8:30 and before teaching his own section two hours later, he often went back to his office to replan. Our observations, followup conversations, course design sessions, daily lesson planning, and frequent emails were all part of our process of exploring and then rendering more visible pedagogies most promising for teaching in a Web 2.0 environment. Clark (2002) underscores why our recollections are so valuable: because researchers are most importantly participants in their lives, not only will they 
have participated (and be participating) in their experience, but their recollections will be an explicit means of framing understanding (Ansbacher, 1947; Clark, 2002; Pearson \& Wilborn, 1995). Investigating our differences in pedagogy through this narrative inquiry has lead to our most creative insights for future iterations of teaching this course. This discursive approach extends our individual writing and has opened spaces for ongoing interpretation of our research.

\section{Sean}

For me, the GI151 course did not begin in September, 2008. Earlier that year, the last question at my interview for a position in Secondary English Education was, "If we were to develop a new writing course for first year students, what advice would you give us?" Given the question again, having taught a section of the course, I would take the opportunity to compare teaching first-year university students to teaching grade 12 students in British Columbia.

Thinking of the difficulties in making a traditional academic writing course more responsive to an increasingly interconnected Web 2.0 world, and thinking of the pedagogical possibilities in teaching writing via social media, I would offer to the interviewer the following advice: 1 . Interrogate the academic paper as the defacto standard for assignments; 2 . Rigorously and vigorously contest standardized "outcomes" across the course sections; and, 3. Utilize the Web 2.0 technologies to both, a) appeal to net generation learners who use these technologies in their personal lives, and b), grow a sense of student agency by connecting their writing with realtime audiences. The following three narratives, woven in between Sandy's reflections, correspondingly amplify my answer to the question I had encountered in my interview.

\section{Sandy}

I posed the question to Sean during his interview because for me the course had begun in the summer of 2007 when I joined a cross-disciplinary committee to review the status of undergraduate academic writing at UPEI and to recommend options for change. In March 2008, based on the options paper developed in this process, the UPEI Senate approved Global Issues 151 as the mandatory introduction to academic writing and thinking for first-year students. As a former high-school English teacher and a member of the group that finalized the course design, I was curious as to the ideas someone more recently out of the Grade 12 classroom might share.

Our planning committee felt that student success and retention in university depend at least partially on the strengths of the relationships they form in first year, and that learning to write is part of a larger social process that includes reading, discussion, writing, and critiquing one's own work and the work of others. We therefore included senior students to facilitate discussion, small-group work, and assist with class writing activities. We agreed upon three relatively broad themes, Social Justice and Population Health, Science and Technology, and Globalization and Governance, each supported by a range of print and other media and culminating in progressively more sophisticated writing assignments.

Tenured and sessional faculty in Arts, Science, Education, and Nursing teaching the course were assisted by a guest speaker for each theme. Thus, social documentary photographer Carlos Reyes-Manzo addressed students about his work in oppressed communities around the world, the well-known science journalist and author Jay Ingram provided a keynote on science and the environment, and Worldwide President of McNeil Nutritionals, Debra Sandler, presented on succeeding in a global marketplace. 
Drawing on the New London Group's (2000) focus on digital technologies as the second shaping force of the 12st century, the course integrated several technologies. The Moodle course management system, for example, became both a resource for coordination and sharing among instructors and a medium for interaction, sharing and discussion between students. Guest presentations were redistributed as podcasts for students who could not attend them in person. Library staff introduced searching for information on the library systems, and instructors had access to live Internet and data-projection systems during classes.

Given the diverse nature of the planning committee in terms of disciplines represented and pedagogical orientations, reaching a consensus on this broad course framework was challenging. Possibly the most contentious issue was the tension between professor autonomy and section consistency. With a brand-new course and a range of professor interests, expertise, and experience, how could we insist that each section be the same? Given that it was a single course and that students would be expecting consistency in terms of workloads and assignments, how could we not? Working through these issues, we developed a draft course syllabus which we felt achieved a reasonable balance between prescription and autonomy. We presented this draft for feedback to course instructors in July, 2008. One of those instructors was Sean.

\section{Sean}

Aspects of Sandy's story unfolded during my meeting with the Dean of Education in March, 2008. While pitching the opportunities of a new (think experimental) course being offered for September, 2008, he was also clear about the surrounding controversy; namely, that the course was previously English 101, the basic academic writing course for first year students. How could studying global issues possibly lead to writing success? The headline that appeared in the local newspaper, "Move to end UPEI English course garners plenty of opposition" sums up the controversy (Wright, 2008).

But I was excited. And I began to dream the course. This course dreaming is what excites me about being a teacher. I love ideas, imagining their implementation, imagining students engaged in work in ways that are deeply meaningful to them. My first thoughts were on how to provide authentic opportunities for students to be active in a learning community of their own creation (Wiebe, 2008a). My own journey as a writer informed my practice of creating projectoriented writing communities (Wiebe, 2008b). I'd learned that all writers, regardless of how far along the writing journey they are, need time and space for their critical creativity.

Combining my tendency to dream a course with an enthusiasm for implementing technology, I thought of having the students start blogs, launch campaigns, post Youtube videos, and so on. With Web 2.0 tools and environments, creating authentic writing communities seemed so much more possible. While learning communities have been heavily critiqued for their tendency to create exclusions and deny difference (Chinnery, 2006; Young, 1990), the online possibilities in social media offer generative possibilities because of multiple belongings and particularities. Dobson (2005) has had success developing web communities for literacy, and notes that while they are messy and challenging, they do "prompt discussion" and "encourage experimentation" (p. 132). Joyce (1995) underscores such benefits, noting that social media (for the mid 1990s this was hypertext) "requires a capability to act: to create, change, and recover particular encounters within the developing body of knowledge” (p. 42). For me, the social orientation of writing and the possibility to reach a real audience in real time offered the kind of experience which only a few years ago was egregiously difficult to implement. In the past, 
hoping to find authentic audiences for students, I arranged for them to write letters to students in other countries, to write letters to the editor, to write children's books and read them to lower grades, to submit opinion essays to small literary magazines, and to write up interviews as freelance writers (one student even doing a phone interview with Michael Andretti).

Only a few days into my new position, I attended the first GI151 instructors' meeting. In addition to meeting the other instructors, the purpose was to ratify a common course syllabus. Like most rookies, I attended wide-eyed and wanting to make a difference. I also went in unprepared for its affect on me. Reflecting back, I see the obvious tensions, which weren not so obvious then. How did all my course dreaming fit into a common course outline? How did my research and experience with project-oriented writing communities complement the requirement for three academic papers? How did my utilization of Web 2.0 technologies in the high school classroom transfer to the university setting?

\section{Sandy}

Although both English teachers, Sean and I are nearly a generation apart as educators: my BEd barely gave me an hour-and-a-half with an Apple II and Lemonade Stand. That exposure taught me barely enough to turn on the computer and select the boot drive, but it convinced me that digital technologies might provide new ways to engage students in taking up and exploring knowledge. My interest in digital technologies had been further validated by seventeen years as a white, middle-class, English-speaking, male educator in a remote northern context where most of my students were Inuit, spoke Inuktitut as their first language, and were far less successful in school than the students who were culturally and linguistically more like me. In this context, innovation included such things as creative drama and classroom configurations similar to those Sean describes, and forays into the emerging digital worlds of desktop publishing (McAuley, 1990), computer mediated communication (McAuley, 1995), and networked collaborative knowledge building environments (McAuley, 1998, 2001, 2004, 2009; Scardamalia, 2002). The last of these, knowledge building, provides a pedagogical framework for the educational use of Web 2.0 in its focus on student control, student agency in knowledge creation, and media convergence supported by digitization, while the environment itself, Knowledge Forum, can be seen as a technological precursor (McAuley, 2007).

Experiences with these digital technologies for student-directed learning led me to believe that it is less what Web 2.0 technologies can do than their ubiquity that is revolutionary. In the late 1980s and 1990s educational innovators defined the technologies such as Knowledge Forum used in classrooms. A decade later, however, students are fluent with a range of freely available digital technologies with similar educational potential. Those technologies, however, are for the most part excluded from schools. As an instructor in the educational technologies courses in the UPEI Faculty of Education, I noted the increasing fluency of students with digital technologies. I saw the new GI151 course as an opportunity to see how these new technologies could be levered into more productive learning.

Unlike Sean, I had been extensively involved in the planning and design of the Global Issues course. However, just like Sean, I approached teaching it with a similar mixture of anticipation and trepidation. 


\section{Sean}

Sandy mentions how Web 2.0 technologies are often excluded from schools. My experience in schools is similar: English teachers are concerned with the use of social media impairing the development of good writers. Not typically asked in schools is how the nature of writing might be changing, specifically its privileged place in society. Some, like Olson (2006), argue for a strong representational quality and place written text at the centre of human communication. From such a theoretical stance, emergent technological opportunities that affect writing and the teaching of writing are evaluated according to traditional textual values. The typical conclusion following from this text-centered theory, is to keep social media out of schools. Others, like Nystrand (2006) argue that "writing and speech are functionally inequivalent” (p. 160). From this theoretical position, new opportunities in technology are not evaluated based on written textual expectations, but as their own, independent discourses. Online chats, blogs, wikis, You Tube posts and other social media can be understood as separate discourses, which, it seems, are gaining status and value in society as a means to convey influence.

Sandy and I do not find the new/old dichotomy useful. Our theoretical position is that whatever comes next in technology ought to be evaluated on whether writers (and we use this term loosely) are empowered, whether their ideas (written, spoken, produced, or performed) are carried by the medium in ways that influence an audience. In this sense, our theory is aligned with critical literacy, and when reflecting on technological innovation in English Language Arts classrooms, we are concerned primarily with the uses to which students and teachers put technology and the obstacles they face in doing so. My chief question to new technological innovation is whether it is likely to be used in ways that value students' words in the classroom and beyond.

It this theoretical position that I brought to my first GI151 meeting, and early in the meeting, my enthusiasm was challenged. Like its predecessor English 101, GI 151 is a mandatory first-year course with multiple sections and 15 different instructors. One's dreamed course may have little relevance on an agenda to reach a common consensus on "the course" we are going to teach. Put forward in successful sounding language, having a course usually implies that each section cover the same material, with the same learning outcomes, the same readings, and the same kinds of assignments. This coherence gives students confidence that they get the the same experience, the same work expectations, and the same grade regardless of their section.

When I pitched my Freirian idea of praxis, of students going out and learning to write by particpating in their community as agents of change, even when community is understood in virtual terms, as in Facebook, or blogs, or wikis, the blank smiles greeting me in return suggested I was from another planet, virtual or otherwise. At the end of the meeting, we left with a common syllabus. It was outcomes oriented and had three fairly traditional assignments: a personal opinion piece (such as a letter to the editor), a response piece (meant to demonstrate one's ability to read critically, judge the quality of one's sources, and formulate an argument), and a final paper.

Why did I support a common but restrictive course outline? Was the shift from English 101 to GI151 just going to be a name change or simple content shift? Were the ghosts of past English 101 teachers in the room haunting us with the need to teach grammar and rhetoric so that 
in the last three years of their university degree students would be able to write a traditional academic paper?

One factor influencing my support for a restrictive syllabus was the power dynamic between rookies and long-timers. As well, after debate had gone round the table a few times, expedience dictated that we wrap things up and not try to change the world at this meeting. And lastly, I felt I would work between the gaps, finding openings and possibilities in the white spaces between the learning outcomes.

In practice, I did shift the assignments so that the personal opinion piece became an "I believe" assignment where students articulated a global issue that was meaningful to them. In the second assignment, instead of having students research a new topic, and in effect, write a traditional academic paper, I asked them to write a "reply" to another student's "I believe" essay. The hope was to create dialogue and a more immediate audience. In the third assignment, I assigned the traditional academic research paper.

With the exception of the second assignment, I feel I was too concerned with meeting the learning outcomes of the common course outline. Next time, I would have all three assignments grow out of larger, more socially constructed project. I would have the students negotiate and construct together a blog that addresses a global issue which matters to them. Such an assignment does align philosophically with my beliefs about learning and would provide many opportunities for students to write actively, both socially and independently, all the while using the latest Web 2.0 tools.

Ironically, looking back, the common course syllabus probably did not eliminate this approach for me. While I did use utilize collaborative online composing and revising software for each assignment (Google docs), and while I did have students interact with me and each other in real time using their laptops in class (Etherpad), I still feel I fell short of the kind of work I did with my students in high school.

\section{Sandy}

Sean's recollection of the Global Issues meeting is a fascinating counterpoint to mine. Assisted by the Global Issues program coordinator, I had been instrumental in planning the meeting and chaired most of it. I had also done substantial work on the version of the syllabus brought to the meeting for discussion, revision, and approval, and felt it provided a reasonable compromise between consistency and flexibility, addressing the critics' concerns with the decision to demote English 101 while creating a framework for literacies that extended beyond rhetoric.

Perhaps because of the extent of my involvement in planning Global Issues and possibly because I was entering my sixth year as a full-time faculty member at UPEI, I felt much less constrained by the syllabus than Sean. I understood and supported his wish for a Freirean approach to the course, but given the range of faculty involved-many of them sessionals who had not been involved whatsoever in the planning-I understood the need for a single coherent syllabus, a degree of consistency across sections, and a balance between innovation and familiarity. During planning we had discussed several ideas for creative simulations, some of them involving innovative uses of technologies, but the scope of implementing them across an entire first-year cohort in the limited time available was inconceivable. I felt relatively comfortable that I could innovate within these constraints. 
Sean called me "Dr. PowerPoint" because of the extent to which I integrated PowerPoint presentations in my class. I do not consider PowerPoint a particularly innovative technology, particularly within a Web 2.0 framework. However, it is a useful tool for pulling together a class "road map" and for generating focus activities. For example, my first class began with a slide show of current photographs of global events integrated with REM's (1987) "It's the End of the World as We Know It": I wanted something to capture students' attention and frame the idea that rarely, if ever, in human history has the rate of change been so rapid, and the potential consequences so dire. PowerPoint also enabled me to frame video that I created myself or that I linked to from YouTube. While definitely a tool for transmission, PowerPoint provides a medium which can be used to stimulate discussion and other forms of interaction.

Moodle, the learning management system used at UPEI, became a medium both for transmission and transaction. In the first case, I used it to supplement the course syllabus and create a persistent, accessible repository of additional readings, resources, and responses to student questions. After a frustrating experiment with a collaborative project module, I created small-group writing circles using the bulletin board function. Writing well grows from writing regularly and often, with regular feedback, but it also grows from reading critically and often, and articulating how a piece of writing might be improved. While rudimentary and not a complete replacement for face-to-face interaction around writing, the Moodle bulletin boards did allow us to extend what was possible in the face-to-face sessions. Students created drafts and were able to edit and revise them according to peer and mentor feedback. Thus, each assignment was reviewed and revised twice before submission. With the students' permission, I was able to use student work for whole-class critiques and suggestions.

MindMeister, a collaborative mind-mapping program, provided a slightly more innovative use of online technology. As we moved from one major theme to another during the course, I brought the site up on the class data projector and we brainstormed the interrelationships between what students knew about the topic and what questions they had. Basic access to MindMeister is free, so I could share the resulting mind map with students who wished to build on it further. Alternatively, I could export the mind map in a number of common formats and upload it to Moodle for downloading. The mind maps became touchstones for summarizing our growing understanding of a theme and starting points for individual writing projects.

One of GI 151's more interesting efforts to move beyond "traditional" writing projects was the designation of the second project as one which could use alternative media to text. Three groups of students took advantage of this choice to create video productions that respectively explored "the great pacific garbage patch", hybrid vehicles, and fair trade practices. All the productions required original research, and the chosen format led to community sources in two of the three productions as well as the library. It is fair to say that the video production required a much greater commitment than a writing assignment: the group working on hybrid cars had had no previous experience with video production, yet created an extremely credible and coherent project. With the students' permissions, their videos were shared in class and posted to the course Moodle site.

\section{Sean}

I wonder why my propensity and enthusiasm for course dreaming did not have enough influence to actually propel me toward taking greater risks in my implementation of technology. 
With my visiting Sandy's class and he mine, what changes was I able to make as the course unfolded? How were my experiences of the course related to the students', and to what extent was I able to respond to their emerging needs? With these questions, this inquiry moves toward some concluding thoughts: it is my intention to reflect on teacher anxieties and hopes around what has changed and might yet change with respect to the latest digital technologies and their influence on classroom practices. Implicit in this question is how these changes might affect the fluid and responsive nature of teacher planning or the student's expectations for what makes a "good" course.

The course dreaming I refer to above requires that teachers feel a kind of freedom that shifts the nature of their responsibility. In general practice, if teachers were to feel responsible primarily to empower the students in the here and now rather than feeling responsible to the curriculum as planned (Dewey, 1938), classrooms would be more open to innovation. In our context, institutional traditions, curriculum, and classroom practices carry on as usual. Reform efforts, according to Yagelski (2005) have made little difference (p. 266). The metaphors which ought to have, by now, provoked change in the nature of a teacher's responsibility, such as teachers acting as mere domestic workers (Pinar, 2004) or teachers exploiting students by making deposits in a banking system (Freire, 1971), have done little to change the traditional pre-planned, transmission-oriented practices that have been in place for the last 120 years (Cuban, 1993; Yagelski, 2005).

Hopefully, Web 2.0 technologies might yet act as a catalyst for change. One obstacle, I suspect, is something Postman (1992) describes as a common phenomenon in human perception, that of rear-view-mirror thinking. Characteristically ironic, Postman (1992) wonders why the blacksmith embraced the technological innovation of the automobile or why the iceman similarly embraced refrigeration. Perhaps, speculates Postman (1992), they did not see the demise of their occupations because technological advances, in their promise to change our lives for the better, are innocently put forward as additions or adaptations, and should one choose to still ride one's horse to town that option will always be available. This "rear-view-mirror" thinking about technological advancement makes it difficult to anticipate how our lives are inherently changed.

Tremmel (2006) confirms that the way we "think" about our discipline will both advance and limit change (p. 10-11). In our university context, evidence for rear-view mirror thinking is found in the widely accepted view that using Powerpoint or Moodle is cutting edge. What has changed from chalk-and-talk to Powerpoint? What has changed for students in being able to upload assignments online electronically instead of passing them in, in class, in person? Using Moodle as a classroom interface and using online tools for conducting searches for information has never really felt cutting edge to me. To rephrase Postman, what are we not seeing in the technology with respect both to the promises made and the experiences lost?

When it comes to course dreaming, then, with increasing possibilities for use of digital technologies in the classroom, the possibilities and responsibilities for change are still before us to be discovered, especially when we remember that technology offers the opportunity to understand classroom practices as inherently different rather than an add-on or adaptation of traditional practices. As a brief example, I will consider why a university writing instructor might want to offer a course called Global Issues instead of English 101. Of course, this assumes differences other than a simple name change. 
When students boot up today they have access to a global audience. For the writing teacher, as Ellis and Caldwell (2005) note, increased confidence of a writer's voice correlates with empowerment. Web 2.0 technologies might be used in ways to facilitate student awareness of how much their words, ideas, artwork, and so on can influence. Participating in a Global Issues course should increase student confidence in the efficacy of their own words, with increased motivation to act as change agents in the communities that matter to them. To me, this is an essential part of what it means to be a global citizen.

Alternatively, it is important to point out that voice develops in an environment where youth are consulted and listened to. Technology could just as easily be a hindrance to empowerment, as, presumably, the very best PowerPoint presentations would resemble Hollywood movies, and voiceless students now positioned as consumers would leave class highly entertained. I asked above what student expectations are for a "good" course? Taking good to mean moral, or ethical, or responsible, teaching in a technological age would mean adapting the classroom environment so that students can participate in meaningful learning, which leads to a feeling of empowerment. This means providing for student writers the roles and opportunities where they can make decisions, can contribute to the community, and can make an actual difference in some legitimate way. My hope is that Web 2.0 environments and learning tools will be a catalyst for new ways of understanding the classroom space.

\section{Sandy}

As I think back to GI151 and the deeper understandings that are emerging through the process of writing this paper, I am drawn to two main conclusions. The first is the normalizing effect of the first-year university culture; the second is the range of challenges facing us as we attempt to develop first-year university experiences that integrate and take advantage of the new technologies that pervade our students' lives and the new literacies they imply.

GI151 at UPEI was intended to address a number of issues: introduce students to the writing skills and practices that would help carry them through a successful undergraduate program, develop collaborative approaches with mentors and peers that would contribute both to better writing and engagement in post-secondary education, deepen their understandings of their relationships to the global contexts and issues that will increasingly shape their lives, and tap into the literacies, media, and technologies that can and will mediate their interactions with each other and the world. It was a radical departure from the course it was intended to replace, and the contentiousness of its introduction put it under intense scrutiny from a number of vested interests at the university. Intended to placate as many as possible of those vested interests, the course syllabus seemed a straightjacket to Sean and reasonably flexible to me. Possibly because I had been involved in writing the syllabus, I felt less constrained by it, particularly with respect to the use of technologies.

Although less constrained, I cannot say that I was not constrained at all. UPEI has mandated Moodle as its course management system, and while this simplifies support and ensures a consistent framework around which to develop blended instruction (at least for those who use it), it isn ot necessarily the best tool for all tasks. Sean did not use it at all and my use was restricted to a large degree to sharing resources, first, because the interactive project module was not ready and, second, because the tools to support collaboration (or at least my understanding of them) were too rudimentary to support what I had hoped to do. For both of us, the university's choice of instructional technology was a constraint, albeit it to different extents. 
Although I had some limited success with the Moodle system, and both Sean and I were able to pull in other technologies to increase student engagement with each other's writing and with global issues in general, the disjuncture between what Sean calls "dreaming the course" and the reality reflects a deeper disjuncture at the pedagogical level. Sean contrasts a transmission orientation to instruction to the transformational orientation of Freierean praxis. Ironically, despite some successes in structuring transactional engagements around the notion of the writers' circles using the Moodle bulletin boards, the closest my students got to the latter was in the presentations for which they were able to choose both the topic and the medium of their treatment of it.

Technology use is a reflexive process that shapes both the user and the task; however, the choice of technologies and the uses to which they are put are to various extents the result of decisions by the user. In cases of instructional uses of media, these decisions are fundamentally pedagogical choices. PowerPoint, for example, can be reduced to a glossy adjunct to transmitting information, and, arguably (Tufte, 2003) one which lends itself to oversimplification of complex ideas. Alternatively, it can be seen as an art form (Byrne, 2003) or a vehicle to structure and provoke transactional engagement with concepts. The technology is the same, and it may be restrictive, but its restrictions may be transcended and transformed to some degree by the pedagogy in which it is embedded.

As instructors, we cannot deny the importance of a globalization fuelled to a large extent by the exponential growth of digital technologies. Neither can we deny the increasing fluency of our students with these technologies as they enter our classrooms. Recognizing these trends does not necessarily mean acceding to them. Rather, it means interrogating them, understanding something of the kinds of learning that our students will likely require over the next thirty years and shaping our pedagogy accordingly. The read/write potential of Web 2.0 technologies lends itself to the creation as well as the consumption of knowledge. A society in which power, wealth, and well-being are increasingly linked to the capacity to create and apply knowledge argues that understanding this potential and acquiring the skills to tap into it are therefore of great importance to our students. While implementing GI151 provided us with a framework to begin to address these issues with the integration of new technologies into our classes, it also highlights the challenges and complexities of successfully doing so in the university environment. 


\section{References}

Ansbacher, H. (1947). Adler's place in the psychology of memory. Journal of Personality, 15, 199-207.

Bruner, J. (1985). Narrative and paradigmatic modes of thought. In E. Eisner (Ed.), Learning and teaching the ways of knowing: 84th yearbook for the National Society for the Study of Education (pp. 97-115). Chicago: Chicago University Press.

Byrne, D. (2003). Envisioning emotional epistemological information. Göttingen, DE: Steidl.

Chinnery, A. (2006). On compassion and community with identity: Implications for moral education. In D. Vokey (Ed.), Philosophy of education 2006. Urbana Champaign, IL: Philosophy of Education Society.

Clark, A. (2002). Early recollections: Theory and practice in counseling and psychotherapy. New York: Brunner-Routledge.

Cuban, L. (1993). How teachers taught: Constancy and change in American classrooms, 18901990 (2nd ed.). New York: Teachers College Press.

Dewey, J. (1938). Experience and education. New York: Collier.

Dobson, T. (2005, Fall). Technologies of text: Reflections on teaching, learning, and writing with/in digital environments. Journal of the Canadian Association for Curriculum Studies, 3(1), 123-137.

Dunne, J., \& Pendlebury, S. (2002). Practical reason. In N. Blake, P. Smeyers, R. Smith, \& P. Standish (Eds.), The blackwell guide to the philosophy of education (pp. 194-211). Oxford, UK: Blackwell.

Ellis, J., \& Caldwell, L. (2005). Increasing youth voice. In P. Witt \& L. Caldwell (Eds.), Recreation and youth development (pp. 281-300). State College, PA: Venture.

Joyce, M. (1995). Of two minds: Hypertext pedagogy and poetics. Ann Arbor, MI: The University of Michigan Press.

Freire, P. (1971). Pedagogy of the oppressed. New York: Seabury Press.

McAuley, A. (1990). By our kamik strings: The Baffin writers' project. Our Schools/Our Selves 3(1), 45-57.

McAuley, A. (1995). Out on the virtual frontier: Experiences with CMC on Baffin Island. In Z. Berge \& M. Collins (Eds.), Computer mediated communication and the online classroom (Vol. 3, pp. 139-147). Cresskill, NJ: Hampton Press.

McAuley, A. (1998). Virtual teaching on the tundra. Technos, 7(3), 11-14.

McAuley, A. (2001). Creating a community of learners: Computer support in the eastern Arctic. Education Canada, 40, 8-11.

McAuley, A. (2004). Ilinniaqatigiit: Implementing a knowledge building environment in the eastern Arctic (Unpublished doctoral dissertation). Ontario Institute of Studies in Education of the University of Toronto: Toronto, ON. 
McAuley, A. (2007, May). Diversity, identity and the new literacies: A case study. Paper presentation at the Canadian Society for the Study of Education Annual Conference. Saskatoon, SK.

McAuley, A. (2009). Knowledge building in an aboriginal context. Canadian Journal of Learning and Technology 35(1). Retrieved from http://www.cjlt.ca/index.php/cjlt/article/view/514/244

New London Group (2000). A pedagogy of multiliteracies: Designing social futures. In B. Cope \& M. Kalantzis (Eds.), Multiliteracies (pp. 9-37). London: Routledge.

Nystrand, M. (2006). Rendering messages according to the affordances of language in communities of practice. Research in the Teaching of English, 41(2), 160-164.

Olson, D.R. (2006). Oral discourse in a world of literacy. Research in the Teaching of English, 41(2), 136-143.

Pearson, M., \& Wilborn, B. (1995). Ann Richards: An Adlerian psychobiography. Individual Psychology, 51, 266-281.

Pinar, B. (2004). What is curriculum theory? Mahwah, NJ: Lawrence Erlbaum.

Postman, N. (1992). Technopoly: The surrender of culture to technology. New York: Vintage Books.

Rice, J. (2006). What should college English be? Networks and new media. College English, 69(2), 127-134.

R.E.M. (1987). It's the end of the world as we know it (and I feel fine). On Document [CD]. Hollywood, CA: Capitol Records.

Scardamalia, M. (2002). Collective cognitive responsibility for the advancement of knowledge. In B. Smith (Ed.), Liberal education in a knowledge society (pp. 67-96). Chicago and LaSalle, Ill, Open Court.

Stanely, L., \& Temple, B. (2008). Narrative methodologies: Subjects, silences, re-readings and analyses. Qualitative Inquiry, 8(3), 275-281.

Tremmel, R. (2006). Changing the way we think in English education: A conversation in the universal barbershop. English Education, 9(1), 10-45.

Tufte, E. R. (2003). The cognitive style of PowerPoint. Cheshire, CT, Graphics Press.

Write, T (2008, Feb 7). Move to end UPEI English course garners plenty of opposition. The Guardian. Retrieved from http://www.theguardian.pe.ca/index.cfm?sid=106127\&sc=98

Wiebe, S. (2008a). A/r/tography: Resonation in writing.In S. Springay, R. Irwin, C. Leggo, \& P. Gouzouasis (Eds.), Being with a/r/tography (pp. 96-109). The Netherlands: Sense.

Wiebe, S., \& Daikow, T. (2008b, May). Assessing poetry in the secondary classroom. Paper presented at the annual meeting of the Canadian Society for the study of education (CSSE): Thinking Beyond Borders - Global Ideas: Global Values. Vancouver, BC.

Wiebe, S., \&, Snowber, C. (2009, Oct). To flourish and nourish with poetry: An intertextual autobiography of spiritual practice. International Symposium of Poetic Inquiry: Poetry as a way of knowing. Charlottetown, PEI: University of Prince Edward Island. 
Yagelski, R.P. (2005). Stasis and change: English education and the crisis of sustainability. English Education, 37, 262-271.

Young, I. M. (1990). The ideal of community and the politics of difference. In L. Nicholson (Ed.) Feminism/Postmodernism (pp. 300-323). London and New York: Routledge. 